\title{
Article
}

\section{Flexible system for micro-clinching processes design and analysis}

\author{
Wojciech Presz $1, *\left(\mathbb{D}\right.$, Han Bing-Yuan ${ }^{2}$ \\ 1 Warsaw University of Technology, Poland \\ 2 School of Automotive and Traffic Engineering, Jiangsu University of Technology, \\ Changzhou 213001, China; hanbing19820223@163.com (H.B.) \\ * Correspondence: wojciech.presz@pw.edu.pl (W.P.); Tel.: +48 696844998
}

Received: 26.02.2020; Accepted: 30.04.2020

\begin{abstract}
With the development of microprocessors, actuators and structural micro-components, new concepts of micro-electro-mechanical systems/machines are constantly being introduced. One of the consequences of this tendency is seeking for best techniques to connect metal micro-components. Because of tools simplicity, no additional fastening parts and the undisturbed structure of the material, clinching appears to be a promising method for joining in micro-scale. A procedure for the analysis of microclinching process is proposed in the paper, and unique, support flexible tooling system designed. This system allows to easily change key parameters of the process. With the use of flexible micro-tooling, a successful micro-clinching of silver sheets of thickness $0.18 \mathrm{~mm}$ has been conducted. An effective numerical method - Rapid Numerical Strength Test - for modelling the process of tearing the joints has been presented. Compliance of key phenomena recognized in modelling with experimental results was obtained.
\end{abstract}

Keywords: micro-joining; micro-clinching; flexible micro-tooling; process modelling

\section{Introduction}

In recent years, one can observe a steady tendency of reducing the size of structural components accompanied with reducing and integrating engineering systems. This can be seen in the field of consumer electronics (e.g. mobile phones, palmtops, etc.), micronutrients for medical applications (e.g. diagnostic chips,

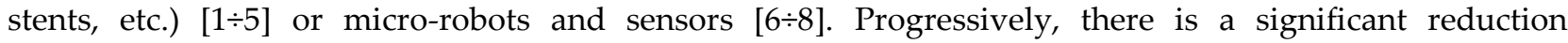
in the size of the parts needed and an increase in requirements for them. In general, it can be declared that development of all kinds of microtechnology is noted as a response to progressing miniaturization. One the main goals of industrial development is the production of components, among which there is a significant share of metal parts of decreasing dimensions. These parts are manufactured by either modified conventional technologies or new ones. A natural consequence of this tendency is the miniaturization of joining processes as well.

Within this work, analysis were limited to mechanical spot joining techniques. Commonly industrially used methods in the area of various metal parts joining are spot welding [9] and laser spot welding [10,11]. In many industries, such as the automotive, also important factor is their ease in mechanization and automation. Both technologies are also used successfully in miscellaneous varieties for miniature objects $[12,13]$. Although, both, regardless of the size of the object, require local heating of the material, which may lead

to structural changes [14:16] and changes of object physical properties [17]. Spot and laser welding have other limitations related to the type and mutual properties of the pair of joined materials and the constitution of their surface layer.

For several years now, a rapid development of joining methods alternative to welding processes has been studied, such as mechanical joining methods [18]. Joining methods that do not change the structure of the materials of the joined components are: various types of riveting or joining by introducing local material deformation: self-piercing riveting and clinching. Traditional riveting and more difficult to design - selfpiercing riveting - require usage of an additional element - a rivet. They are, therefore, extremely difficult to

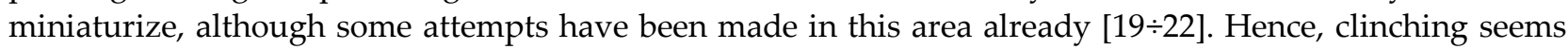
particularly appropriate to miniaturization, also due to the relatively simple tools arrangement. It is becoming more and more common due to the increasing use of alternative materials, that are difficult or impossible to weld $[23,24]$ or modern surface layers decreasing weldability $[25,26]$. Clinching can be used 
when joining galvanized, painted or organic materials. The clinched joints also offer relatively good resistance to fatigue wear [27]. There are many variations of this process [28:30]. The most common is the plain clinching method [31], which outline is shown in figure 1. It involves establishing a mechanical joint of two layers by their deformation leading to the formation of a characteristic interlock, "u" (Fig. 1b) [32]. The clinching takes place in four stages, figure 1a: insertion, expansion, filing and backward extrusion. Interlock is formed during the last phase of the process. The advantages of clinching can be summarized as:

- absence of thermal degradation of the material and the coating structure,

- absence of pollution,

- possible joining of various types of materials with different thickness,

- somewhat simple tools and tooling design.

These features particularly promote clinching as a method which could be used in the design of microjoints of modern micro-mechanisms. However, with the miniaturization of the process one should expect analogical difficulties, that occurred in the miniaturization of the metal forming processes. These troubles and complexities caused the development of a new sub-branch of metal forming technology - the microforming [33,34]. What one deal here is the so-called scale effects [35:37], associated with each of the areas of the metal forming process. These include the structure, the preform material and its surface layer [38], in geometrical aspect as well as physicochemical properties. Also, the structure of the tool material and the quality of its surface [39], and even their structure [40,41] is considered. High pressures occurring in the contact areas of tools with materials remaining in the plastic state increase the significance of contact phenomena, which are strongly influenced by the properties of the surface layers of combined materials [42] and the mutual tool - work material properties. According to the analysis of the clinching process, the state of knowledge is already advanced, and the processes are successfully used on an industrial scale. Such materials are definitely missing in relation to the clinching of miniature objects. This work is intended to fill this gap.

\section{Materials and Methods}

The general task was to develop a research methodology for clinched micro-joints, including:

- the formalizations of the micro-joint description,

- flexible experimental stack-up taking into account the microscopic dimensions of the objects,

- numerical modelling techniques supporting research procedures.

This methodology was initially developed based on the implementation of three micro-clinching processes that differ from each other by the different value of one geometric parameter.

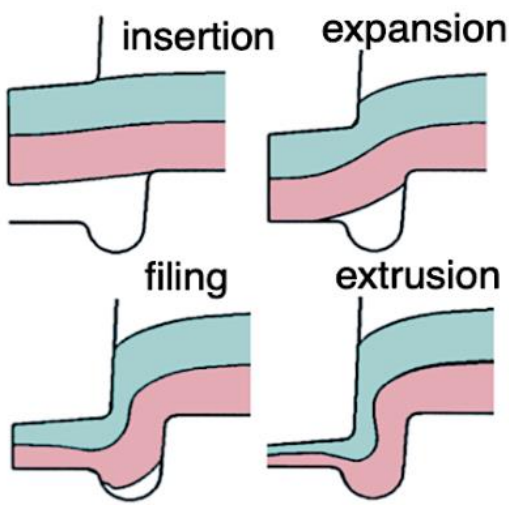

(a)

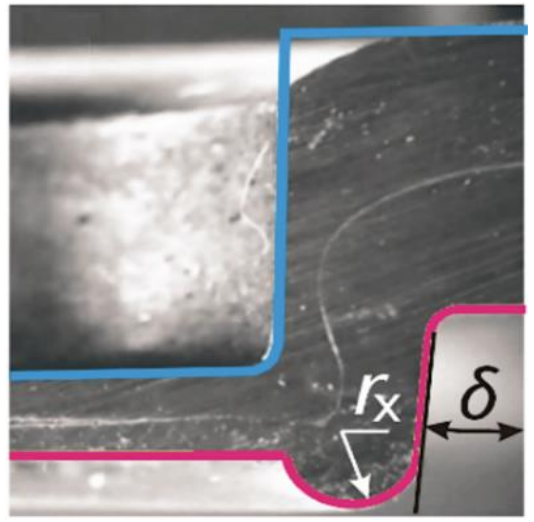

(b)

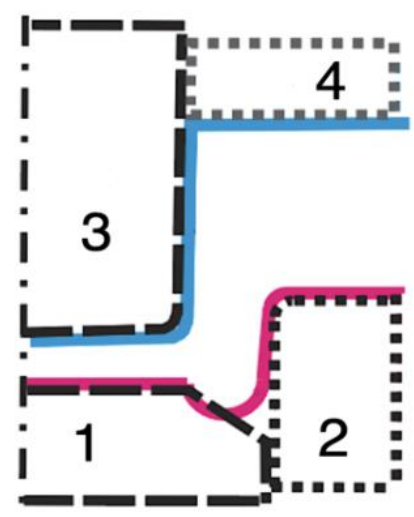

(c)

Fig. 1. a) Clinching phases; b) cross-section of clinched joint - colour lines show outlines of tools, angle $\delta$ and radius $r_{x}$ are not possible to obtain within the flexible system; c) key components of flexible tool system: the lower punch -1 , the die -2 , the upper punch -3 , the blank holder -4

\section{Flexible micro-die set for micro-clinching analysis}

The task that has been specified is to design the tooling, that would allow easy change of the clinching parameters considered as key. It should be remembered that direct scaling of existing designs is usually out of the question, most often due to difficulties in manipulation and positioning of miniature tooling elements. As the base process for miniaturization, the already mentioned clinching process shown in figure 1 was adopted. Shapes of Industrial tools have been reproduced in a simplified way, with two tool pairs (Fig. 1c). Accordingly, the lower punch -1 , the die -2 , the upper punch -3 and the blank holder -4 . 
Each of the components: 1, 2, 3, 4, are simple to design and easy to manufacture (Fig. 2). The top and lower punches are commonly available punches for blanking, with faces modified by grinding. The die and the blank holder are cylinders with holes made by a wire EDM. These structural simplifications also generate some limitations, e.g. the radius $r_{x}$ and angle $\delta$ are not possible to obtain. As a part of this work one pair of clinching punches was used (Fig. 2), that have been combined in three different positions, providing three micro-clinching processes.

\section{Parametrization of the micro-clinching process}

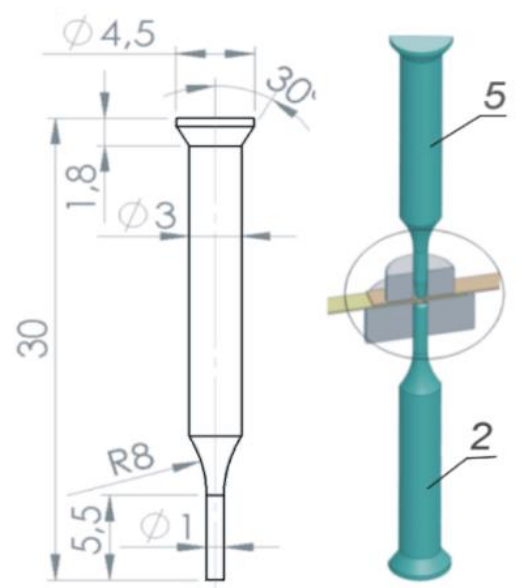

(a)

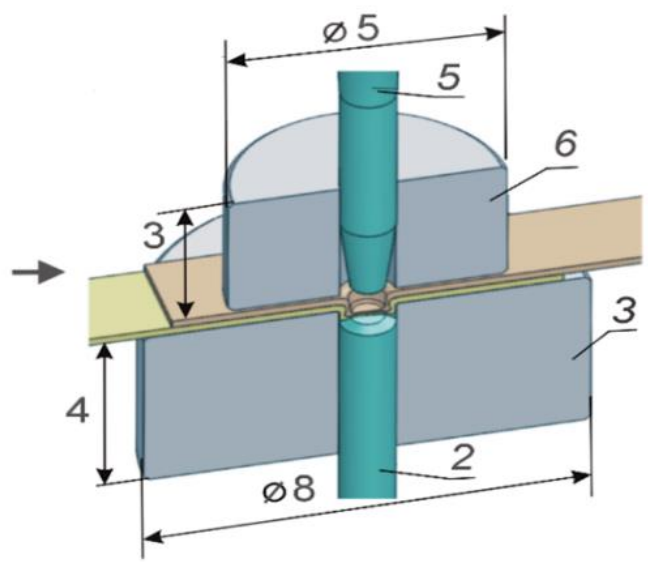

(b)

Fig. 2. Key components of the micro-clinching flexible experimental system (mm): a) popular punch for punching; b) design: 1 - unmovable lower punch, 2 - cylindrical die, 3 - movable upper punch, 4 - cylindrical blank holder

The process of clinching is a process dependent on several geometric parameters and in the literature one can find suggestions for its parameterization and optimization $[43 \div 46]$. The parameterization proposed is original and dedicated to the proposed micro-clinching process. It takes into account the limitations resulting from the adopted tool design. The process has been geometrically parameterized in two aspects: the geometric parameters of tools and geometric parameters of the joint. The geometric parameters of the tools are shown in figure $3 a$.

The punch is characterized by the diameter of the face, $d_{\mathrm{p}}$, the face radius, $r_{\mathrm{p}}$, and the cone angle, $\alpha$. Additional parameter associated with the punch is its maximum immersion, $h_{\mathrm{p}}$. Bottom space of the clinching process consists of two components: lower punch and die, characterized by die diameter, $D$ (which is also the diameter of the lower punch), die radius, $r_{\mathrm{m}}$, the diameter of the lower punch face, $d_{\mathrm{c}}$, the angle of the lower punch face, $\gamma$, the die depth - distance between lower punch face and die surface, $h_{c}$, and the thickness of the neck, $b$, which can also be referred as a side clearance. Additional parameter associated with the punch is its maximum immersion, $h_{\mathrm{p}}$.

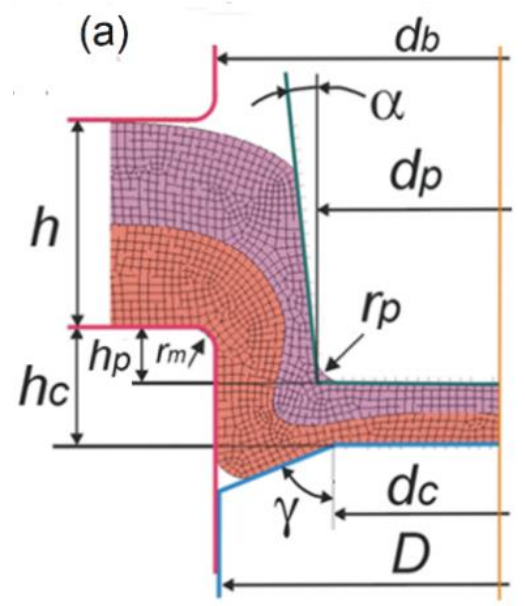

(b)

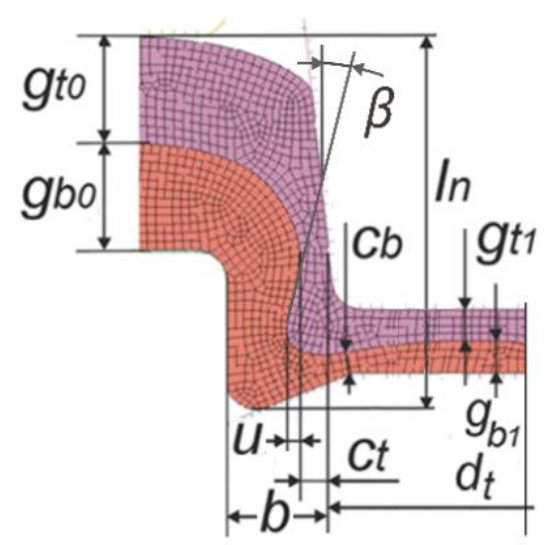

Fig. 3. Representation of proposed micro-clinched joint geometry parameters: a) related with tools; b) related with a joint 
Parameters associated with the blank holder are: its diameter, $d_{\mathrm{b}}$, and the distance between blank holder and die surfaces, $h$ - for the case in which the deformation of the sheets is controlled by a geometric constraint. It should be noted, that the depth of the die can be very easily and arbitrarily changed by setting the lower punch position. The geometric parameters of the joint are shown in figure 3b. These parameters are: initial thickness of two sheets, $g_{\mathrm{b} 0}$ and $g_{\mathrm{t} 0}$, the thickness of two sheets in the bottom area, $g_{\mathrm{b} 1}$ and $g_{\mathrm{t} 1}$, the top sheet necking, $c_{\mathrm{t}}$, it's angle $\beta$ and internal diameter, $d_{\mathrm{t}}$, lower sheet necking at the bottom edge, $c_{\mathrm{b}}$, and interlock, $u$. The global parameter is the total length of the joint, $l_{n}$.

\section{Flexible micro-die set}

The flexible die set - FDS, enables the micro-clinching process to be carried out with various tool sets described in figure 2. The FDS construction is shown in figure 4 . The body -1 in which the bottom die -2 , bottom punch -3 and its guides -4 and -5 , are mounted, is mounted in a frame -6 , which can slide vertically relative to the base -7 . Its position is determined by spacers -8 . They affect the depth of the die $-h_{c}$, through the plunger -9 with the nut -10 and the bolt -11 . The clinching plates -12 , are placed on the surface of the die and pressed with a blank holder -13 . The pressing is carried out with pressure screws -14 , that move the movable body -15 , into which the sleeve -16 , and the upper punch guide -17 , are placed. The punch 18 , is connected by a nut -19 , to the drive system.

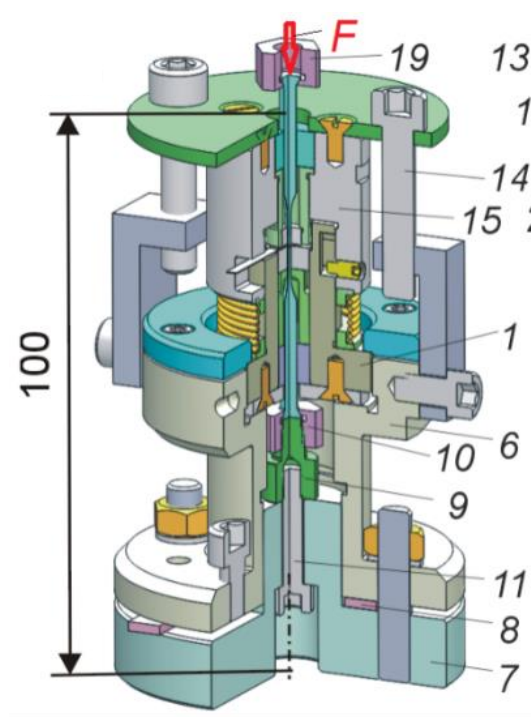

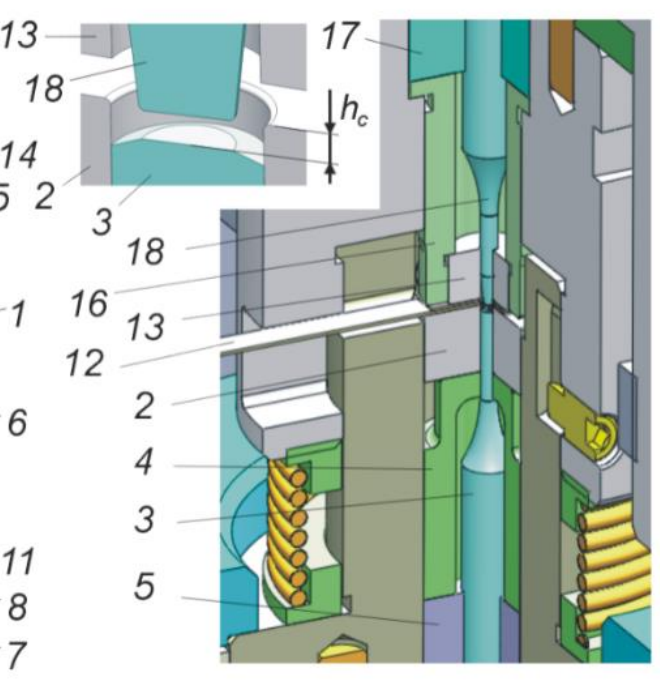

(a)

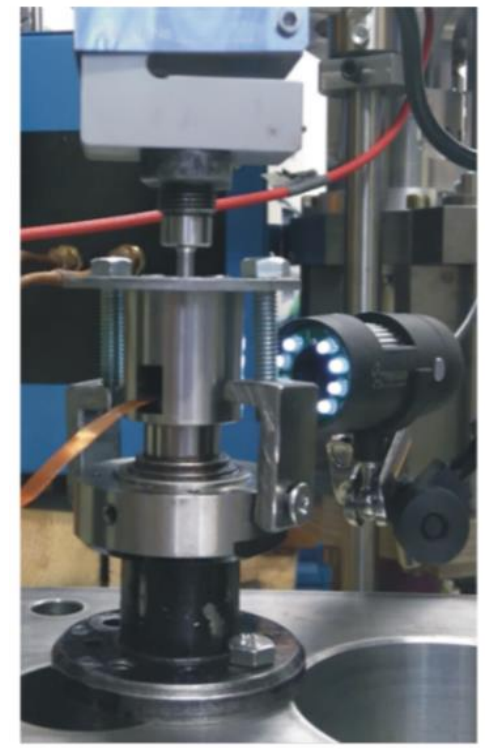

(b)

Fig. 4. Design of the Flexible Micro Die Set for micro-clinching analysis: a) technical drawing - description in the text, F - process force; b) System overview

\section{Results}

Three micro-clinching processes, called Process 1 - P1, Process 2 - P2 and Process 3 - P3 were carried out using punches which pictures are shown in figures $5 \mathrm{a}$ and $5 \mathrm{~b}$. Key parameters of these processes are shown in figures $5 \mathrm{c}$ and $5 \mathrm{~d}$. Tools are placed in the micro-tool set, shown in figure 4 , and is mounted on the high precision testing machine Hounsfield H10KS. Additionally, tool settings are assisted with the special camera, shown in figure $4 \mathrm{~b}$. The tool parameters are summarized in table I. A tape of $5 \mathrm{~mm}$ width and 0.18 $\mathrm{mm}$ thicknesses of pure silver was selected as a material for sheets to be joined.

Table I. Tool and process parameters according to figure 3 , lower indexes 1, 2, 3 refer to $P 1, P 2, P 3$

\begin{tabular}{cccccccccccccccc}
\hline $\begin{array}{c}D \\
\mathbf{m m}\end{array}$ & $\begin{array}{c}\boldsymbol{r}_{\mathrm{m}} \\
\mathbf{m m}\end{array}$ & $\begin{array}{c}d_{\mathrm{b}} \\
\mathbf{m m}\end{array}$ & $\begin{array}{c}d_{\mathrm{c}} \\
\mathbf{m m}\end{array}$ & $\begin{array}{c}\gamma \\
\mathbf{d e g}\end{array}$ & $\begin{array}{c}\boldsymbol{d}_{\mathrm{p}} \\
\mathbf{m m}\end{array}$ & $\begin{array}{c}\boldsymbol{r}_{\mathrm{p}} \\
\mathbf{m m}\end{array}$ & $\begin{array}{c}\alpha \\
\mathbf{d e g}\end{array}$ & $\begin{array}{c}\boldsymbol{h}_{\mathrm{c} 1} \\
\mathbf{m m}\end{array}$ & $\begin{array}{c}h_{\mathrm{p} 1} \\
\mathbf{m m}\end{array}$ & $\begin{array}{c}\boldsymbol{h}_{c 2} \\
\mathbf{m m}\end{array}$ & $\begin{array}{c}h_{p 2} \\
\mathbf{m m}\end{array}$ & $\begin{array}{c}h_{\mathrm{c} 3} \\
\mathbf{m m}\end{array}$ & $\begin{array}{c}h_{\mathrm{p} 3} \\
\mathbf{m m}\end{array}$ & $\begin{array}{c}g_{\mathrm{t} 0} \\
\mathbf{m m}\end{array}$ & $\begin{array}{c}g_{\mathrm{b} 0} \\
\mathbf{m m}\end{array}$ \\
\hline 1.0 & 0.04 & 1 & 0.60 & 80 & 0.60 & 0.04 & 6 & 0.23 & 0.141 & 0.25 & 0.150 & 0.27 & 0.176 & 0.18 & 0.18 \\
\hline
\end{tabular}

Micro-clinching was carried out according to the following procedure:

- inserting $50 \mathrm{~mm}$ long sheet metal strips into the working space,

- closing the working space,

- compress the clamp with pressure screws (Fig. 4a $\div 14$ ),

- implementation of the machine beam motion program:

- approach at a speed of $5 \mathrm{~mm} / \mathrm{min},(8.3 \mathrm{e}-5 \mathrm{~m} / \mathrm{s})$, 
○ working movement at a speed of $0.1 \mathrm{~mm} / \mathrm{min}$, (1.6e-6 m/s),

$\circ$ unloading at speed $0.01 \mathrm{~mm} / \mathrm{min},(1.6 \mathrm{e}-7 \mathrm{~m} / \mathrm{s})$,

○ return movement at a speed of $5 \mathrm{~mm} / \mathrm{min}(8.3 \mathrm{e}-5 \mathrm{~m} / \mathrm{s})$,

o pressure release,

o the work space opening,

$\circ$ joined sheets removal.
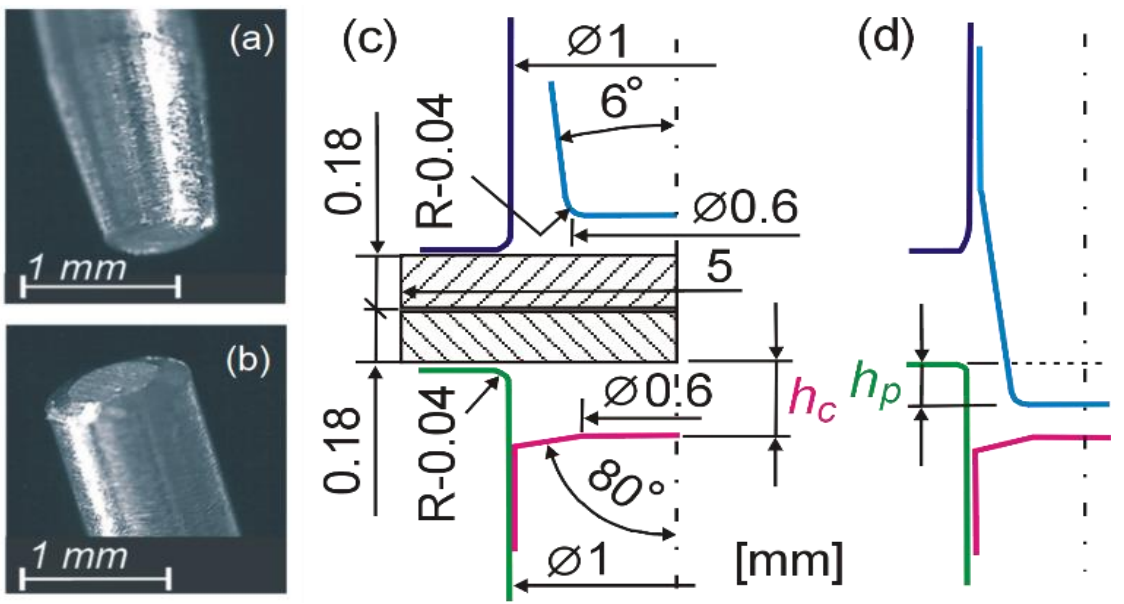

Fig. 5. Key details of test processes: a) movable punch; b) unmovable punch; c) basic dimensions of tools; d) parameters of P1-P3

Process force and beam offset were recorded by the machine data acquisition system. The good repeatability of the force waveforms is noteworthy, which proves the proper stack-up design and the appropriate test procedure, see figure 6a. The mean values of the force records were taken for analysis (Fig. $6 b)$.

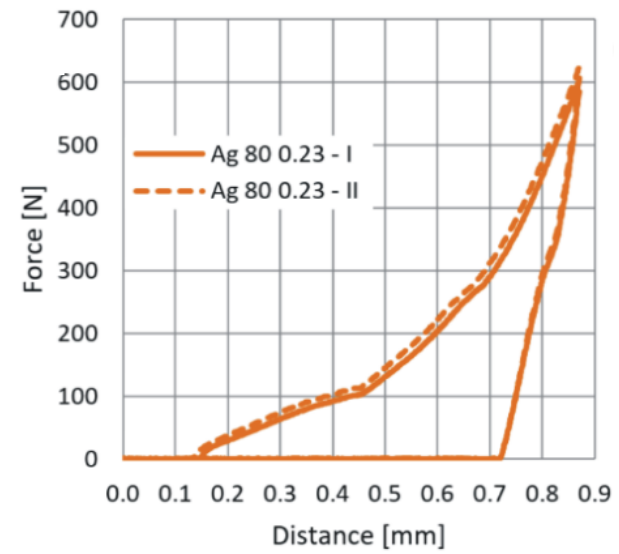

(a)

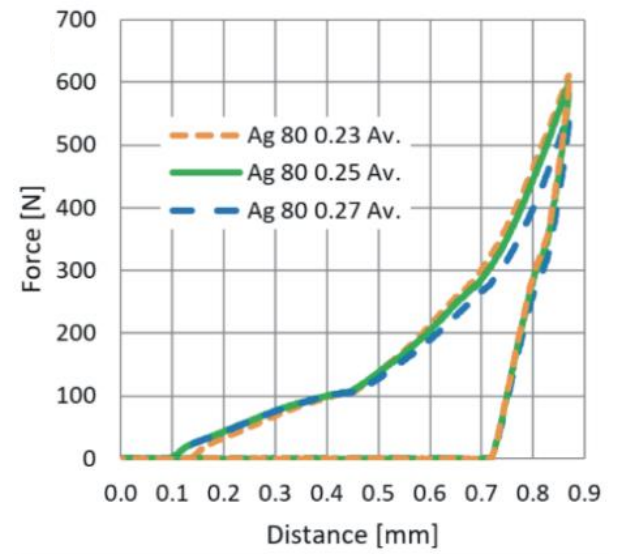

(b)

Fig. 6. Forces recorded during clinching: a) Example of two force flows of $P 1 ; \mathrm{b}$ ) Average force flows of $P 1, P 2$ and $P 3$

\section{Strength tests of clinched joints}

In the case of clinched joints strength analysis, two tests, usually performed in pairs, are recognized: peel test - PT and shear test - ST (Fig. 7). Their popularity is mainly related to the speed and simplicity of their perform and the uniqueness of the results obtained. The tests consist in stretching the joined metal strips to their complete disconnection under particular conditions, with the maximum process force being determined. Technical simplicity of these tests, however, does not mean simplicity of loading. On the contrary, the joints are subjected to complex and evolving three-dimensional states of stress and deformation during loading, which, however, well reflects most of the possible real loads. Micro-joined samples were subjected to peel and shear tests using a testing machine with a ram speed of $0.5 \mathrm{~mm} / \mathrm{min}(8.3 \mathrm{e}-6 \mathrm{~m} / \mathrm{s})$. The samples were fastened using jaws covered from the fastening side with fine-grained sandpaper (ISO - P400) to prevent slipping. Each experiment was repeated for at least 3 times and the stress-strain curves were computed by averaging. The dimensions of the samples and the attachment conditions are shown in figures $8 \mathrm{a}$ and $8 \mathrm{~b}$. The stretching run was recorded using a camera - sample shots are shown in figures $8 \mathrm{c}$ and $8 \mathrm{~d}$. 


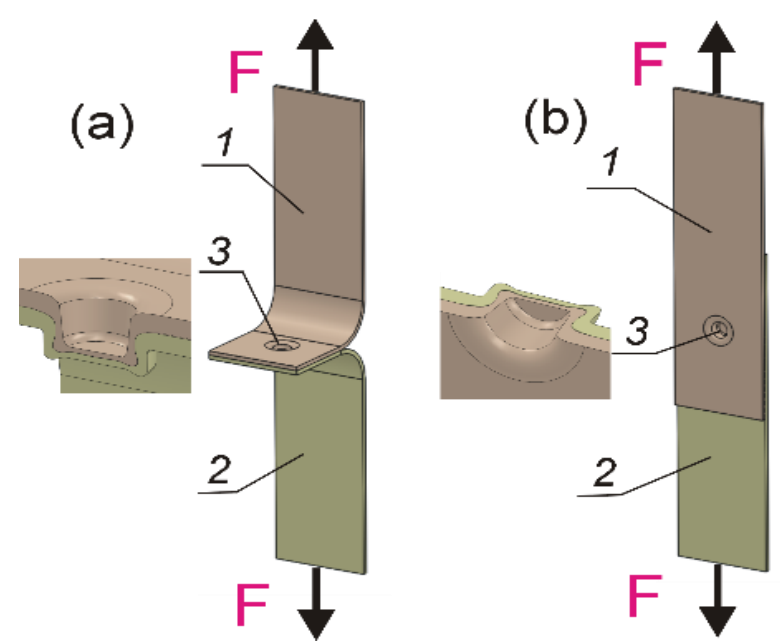

Fig. 7. Strength tests: $F$ - tensile load, 1 - upper sheet metal, 2 - lower sheet metal, 3 - joint; a) peel test principle; b) shear test principle
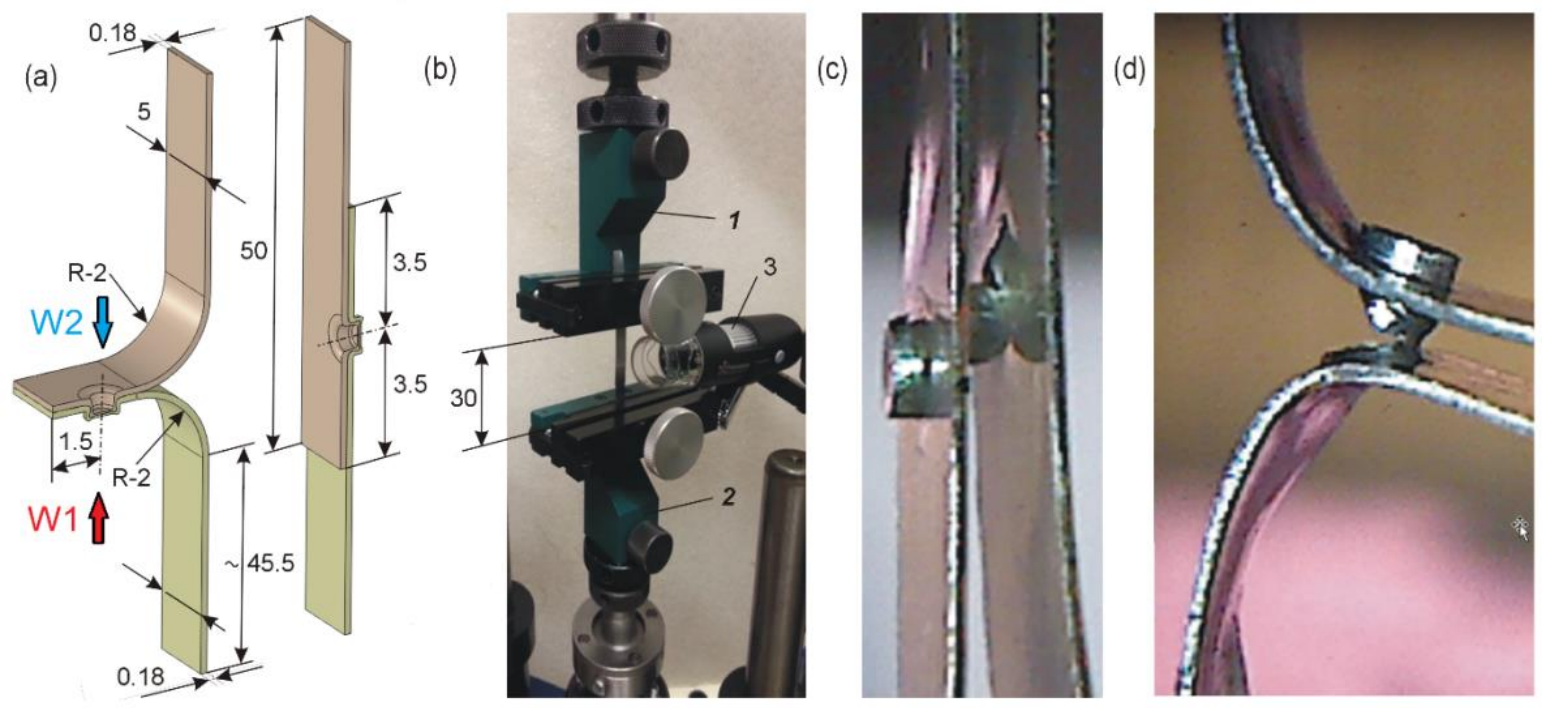

Fig. 8. Joints loading tests: a) Sample dimensions and used in figure 9 directions of photographing joints after tearing: W1, W2; b) Processes conditions: 1 - upper jaw, 2 - lower jaw, 3 - camera; c) a frame of film from a shear test; d) a frame of film from a peel test

Recorded loading process forces and photographs of the joints after rupture are shown in figure 9. In the case of the joint formed in $P 1$, in $P T$ no fracture of the neck of the upper joint part was observed (Fig. 9a and 9b). In other cases, such a crack occurred, but in the $S T$ for the joint formed in $P 1$ and $P 2$ the cup was not detached (Fig. 9c and 9i). In contradiction to $P T$ where the cup has remained in the lower part of the joint (Fig. 9k and 9r) like in ST in P3 (Fig. 9q).

\section{Mechanism of tearing joints in peel and shear tests}

Three phenomena affect the disconnection process:

- plastic deformation,

- friction, $_{\overline{7}}$

- cracking.

The upper and lower cups are gradually deformed. The top cup is squeezed, and the bottom cup is stretched. The parts of the tape between the connector and the holders of the testing machine are also plastically deformed. Friction develops when the upper cup moves out of the frame cup. The fracture affects the neck of the lower cup and develops from the point that is most loaded simultaneously on both sides of the neck circumference. Fracture begins at the most loaded point on the neck of the upper cup and develops simultaneously on both sides of the neck circumference.

The proportion of plastic deformation and cracking largely determines the course of the tearing process. The presented processes $P 1, P 2$ and $P 3$ are an illustration of this. Moving from $P 1$ through $P 2$ to $P 3$, an increasing share of the cracking phenomenon and the weakening role of plastic deformation are observed. 
The reflection of occurring phenomena are the courses of forces of disconnection processes of joints. Plastic deformation causes the decrease in the disconnection force decrease and the "convexity" of the force course.

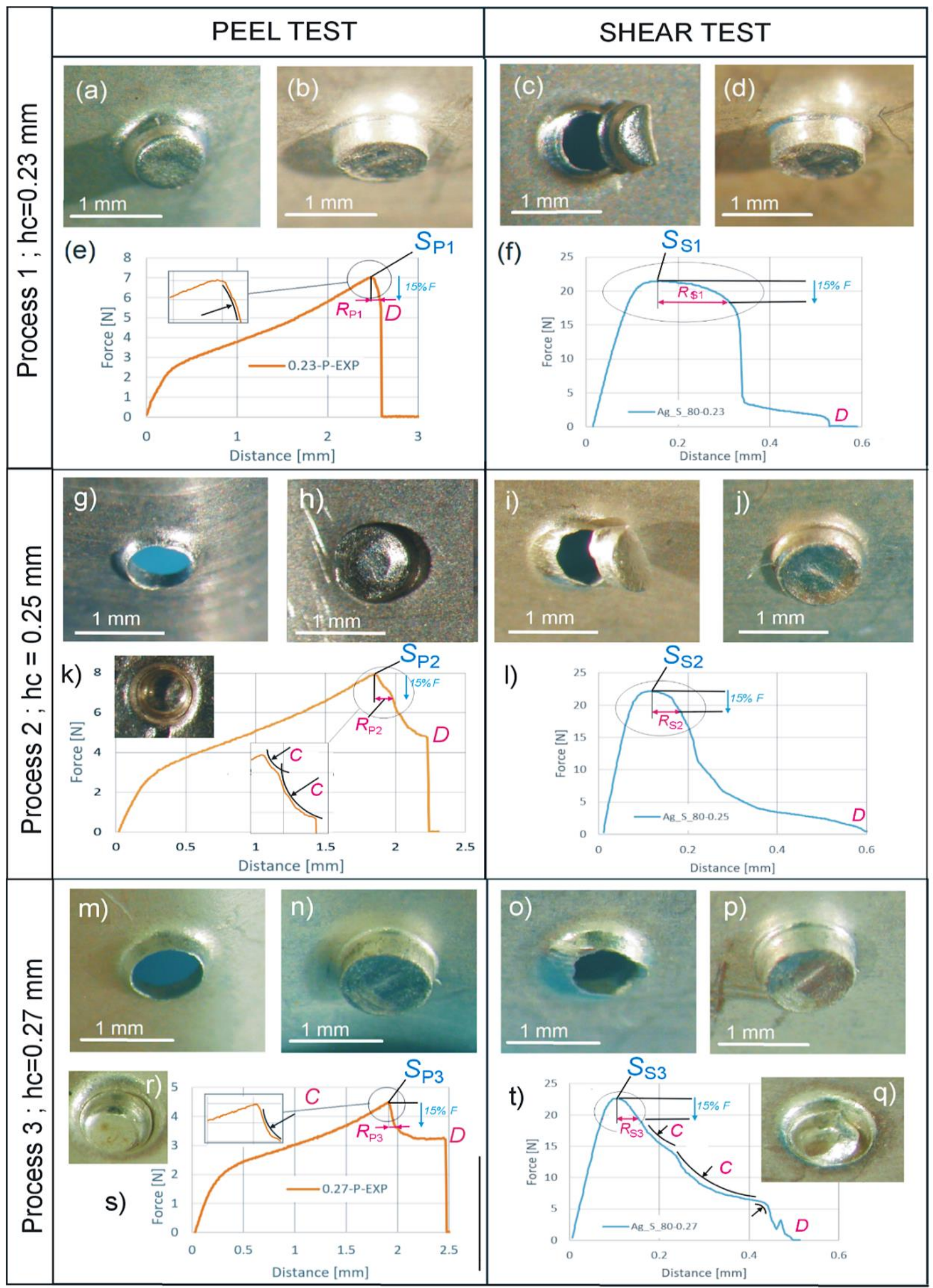

Fig. 9. Joint loading test results: (a), (c), (g), (i), (m), (o) upper sheet metal - direction $W 1^{*}$; (b), (d), (h), (j), (n), (p) lower sheet metal - direction $W 1^{*} ;(\mathrm{k}),(\mathrm{r}),(\mathrm{q})$ lower sheet metal - direction $W 2^{*} ;(\mathrm{e}),(\mathrm{k}),(\mathrm{s})$ : records of tearing forces in peel tests; (f), (i), (t): records of tearing forces in shear test. Detailed description in text; ${ }^{*}$ see figure 8a 
As shown in figure 9e, the strength of the process decreases gently, and the separation of the upper and lower parts without violating the consistency of the upper cup occurs at point $D$. The phenomenon of cracking is a rapid decrease in process force and concavity of its course figure 9s. Here, the upper and lower parts are separated at point $\mathrm{D}$ while the upper cup is simultaneously separated. The course of force in $P 2$ shows the increased effect of plastic deformation - compared to $P 1$. There are two phases of the cracking process, to which the plastic deformation of the cup is applied, slowing the decrease in force. Disconnection occurs at point $D$ simultaneously with the separation of the upper cup, which remains in the lower part, figure $9 \mathrm{k}$. In $S T$, an increase in the impact of cracking and a decrease in the impact of plastic deformation are also gradually observed from $P 1$, through $P 2$ to $P 3$. In $P 1$ and $P 2$, the plastic deformation of the cup occurs simultaneously with the development of the crack. This leads to separation of the joint at point $D$ without complete separation of the cup (Fig. 9c and 9i). In P3, cracking dominates and the joint ruptures with the separation of the cup (Fig. 9o), which remains in the bottom of the connector (Fig. 9q). Separation of the cup is preceded by the deformation of the neck edge visible in figure 9o. The phenomena described affect the tearing force of joints. For the quantitative estimation of the share of plastic deformation and cracking in the analysed processes, the $R$ parameter shown in figure 9 was adopted. It is the range of the tearing force decrease from the maximum value to the value lower by $15 \%$ (1).

$$
R_{i, j}=F_{i, j}^{-1}\left(0.85 \cdot F_{\max i, j}\right)-F_{i, j}^{-1}\left(F_{\max i, j}\right) \quad \text { for } \quad F_{i, j}^{-1}\left(0.85 \cdot F_{\max i, j}\right) \geq F_{i, j}^{-1}\left(F_{\max i, j}\right)
$$

where:

$i=\{P, S\}, \mathrm{j}=\{1,2,3\}$,

$F_{\mathrm{i}, \mathrm{j}}(\mathrm{x})$ - tearing force,

$x$ - distance.

The maximum values of the tearing forces are adopted as the strength $S$ of the joint at a given load method:

$$
F_{\max i, j}=S_{i, j}
$$

The values of the $R$ parameter are shown in figure 11, and the strength values $S$ of joints in figure 15 . The small value of the $R$ parameter at point $A$ is caused by the small interlock value that occurs in $P 1$. This is a reason of a small force needed for the plastic disconnection of the joint.

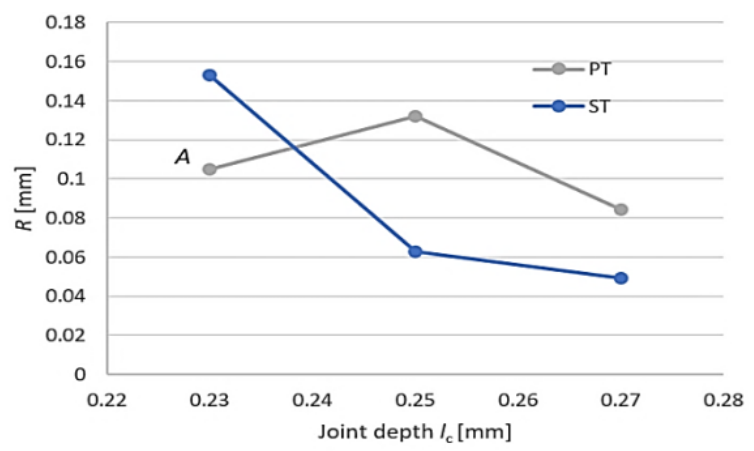

Fig. 10. Parameter $R$ : formally described (1) and shown in figures $9 \mathrm{e}, \mathrm{f}, \mathrm{k}, \mathrm{l}, \mathrm{s}, \mathrm{t}$ is the range on "Distance [mm]" axis in record of tearing force between joint's strength $\mathrm{S}$ and the point on the curve where force dropped $15 \%$.

\section{FEM modelling of micro-clinching process and joint load}

The clinching process - joint forming - was analysed using the finite element method, as a static, 2Daxisymmetric, assuming iso-thermal conditions. Tools - punch, die and blank-holder - were modelled as rigid areas, and the sheet material was described by the elastic - plastic with nonlinear hardening model. Stress-strain curves parameters were obtained based on the ASM Atlas of Stress - Strain curves (Table II). Modelling in a very general way takes into account only the surface effect of the scale, the occurrence of which was marked by adopting high coefficients of friction - COF that is reported in micro forming processes [47]. Volume scale effect was not included because, as it was shown in [48] it has a relative minor influence on a material flow in processes in which the material is in a state of triaxial compression. This condition prevails in the clinching process, indeed. The COF was set 0.2 on the tools and sheets interface (light oil in experiments) and 0.3 between sheets (no lubrication during experiments). 
The material model was enhanced with damage criteria. In most CAE software the micro-mechanical models of Lemaitre, Gurson, Bonora and Oyane, as well as the macro mechanical models of Cockroft-Latham and Johnson-Cook are implemented [49]. In this work the Oyane, a micro-mechanical damage model was chosen. It uses the mean normal stress and thus takes the triaxiality into account, that is important in a such a metal forming process like micro-clinching. The Oyane model defines the cavity growth over the density. In this numerical analysis takes form (3) [50].

$$
\int_{0}^{\varepsilon_{e q f}}\left(1+\frac{1}{B} \frac{\sigma_{m}}{\sigma_{e q}}\right) d \varepsilon_{e q}=D
$$

where:

Eeqf - equivalent fracture strain,

$\sigma_{\mathrm{m}}$ - mean stress,

$\sigma_{\text {eq }}-$ equivalent stress,

$B, D$ - material constants.

The cavity growth is adapted to the material model by parameter $\mathrm{B}$, a dimensionless material constant. This means, that this material constant can vary from case to case and can be determined using tensile, compression or torsion tests. In the MSC. Marc software three parameters: material constant $B$, damage threshold $D$ (accumulation), and element removal threshold ERT can be specified. It was assumed that the material constant used in the current analysis is $B=0.4$. It was estimated based on literature $[50,52]$ and verified in numerical experiments of punching [21,51]. Both damage threshold $D$ and element removal threshold ERT were established during initial analysis of damage parameter level. Damage threshold parameter was set to $D=0.85$. Element removal threshold is strongly dependent on remeshing criteria. The $E R T$ defines a value, where elements will be deleted if the "Damage" value reaches specified value. After remeshing and element removal threshold optimization, $E R T=1.0$ was assumed for the current process analysis. The value 1.0 means that all those elements, which reach this "Damage" value will be deleted.

Table II. Material and friction parameters in numerical modelling

\begin{tabular}{cccccccr}
\hline \multicolumn{2}{c}{ Elastic properties } & \multicolumn{2}{c}{ Plastic properties } & \multicolumn{2}{c}{ Damage criteria parameters } & \multicolumn{2}{c}{ COF } \\
$E[\mathrm{MPa}]$ & $\boldsymbol{v}$ & Stress-strain curve & $\boldsymbol{D}$ & $\boldsymbol{B}$ & $\boldsymbol{E} \boldsymbol{R} \boldsymbol{T}$ & Tools & Sheets \\
\hline 76000 & 0.37 & $\sigma_{\mathrm{p}}=284 \varepsilon_{\mathrm{p}} \mathrm{p}^{0.34}$ & 0.85 & 0.4 & 1.0 & 0.2 & 0.3 \\
\hline
\end{tabular}

Initial optimization of the numerical model was performed to verify the applied type and initial size of the elements, as well as the remeshing criteria and remeshing parameters, with particular regard to the latter. Remeshing settings were crucial since they influence the way how the mesh adapted during simulation, but also influence the final size of the finite elements, especially important around the interlock zone. The 2D flat axisymmetric quadric (four-node) elements were used. Examples of provided distribution of deformed materials in the joint are shown in figure 11.
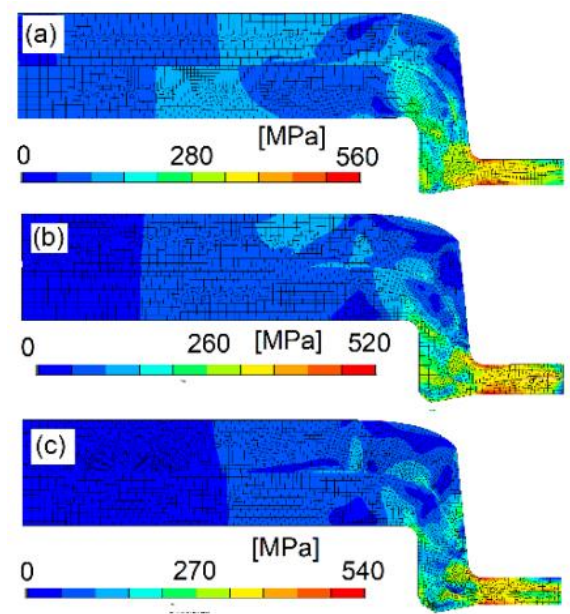

Fig. 11. Distribution of Huber-Mises stress: a) Process 1; b) Process 2; c) Process 3

Key joint parameters are shown in table III. The verification of the correctness of the method adopted was the consistency of the process force. Attention should be paid to the course of unloading forces (Fig. 12), which are similar in each of the analysed cases. The course of force is an expression of the elastic recovery of all elements of the loading system, which consists of a chain of several elements with different stiffness. 
Three of them were considered dominant. The unloading functions were approximated by linear functions in three intervals determined by the distinct changes in slope of the unloading curves.

Table III. Key parameters of the obtained joints

\begin{tabular}{cccc}
\hline $\begin{array}{c}\text { Joint } \\
\text { Parameter }\end{array}$ & $\begin{array}{c}\mathbf{h}_{\mathbf{c}} \\
\mathbf{m m}\end{array}$ & $\begin{array}{c}\mathbf{C}_{\mathbf{t}} \\
\mathbf{m m}\end{array}$ & $\begin{array}{c}\mathbf{U} \\
\mathbf{m m}\end{array}$ \\
\hline Process 1 & 0.23 & 0.0410 & 0.0274 \\
Process 2 & 0.25 & 0.0373 & 0.0323 \\
Process 3 & 0.27 & 0.0314 & 0.0481 \\
\hline
\end{tabular}

The procedure is explained in the figure $12 \mathrm{~b}$. The unloading force was approximated in the ranges of measuring points: $<\mathrm{s}, \mathrm{a}$ ), $<\mathrm{a}, \mathrm{b}$ ) and $<\mathrm{b}, \mathrm{n}$ ), with three straight lines characterized by the directional coefficients $k_{1}, k_{2}$, and $k_{3}$ shown in the drawing. Local component of correction caused by the elastic deflection, corresponding to the point $\mathrm{i}(\mathrm{i}=0$ at point $\mathrm{s}$ ), is given by formula:

$$
\delta x_{i}=\left\{\begin{array}{lr}
\delta^{a} x_{i}=\frac{Y_{i}-Y_{i-1}}{k_{1}}, & i=1,2 \ldots, a \\
\delta^{b} x_{i}=\frac{Y_{i}-Y_{i-1}}{k_{2}}, & i=a+1, a+2 \ldots, b \\
\delta^{n} x_{i}=\frac{Y_{i}-Y_{i-1}}{k_{3}}, & i=b+1, b+2 \ldots, n
\end{array}\right.
$$

where:

$Y_{i}$ - recorded process force corresponding to the measuring point $i$, $k_{1,2,3}$ - the directional coefficients of the lines approximating the relief, $\delta^{a, b, n} x_{i}$ - local components of correction because of elastic deflection.

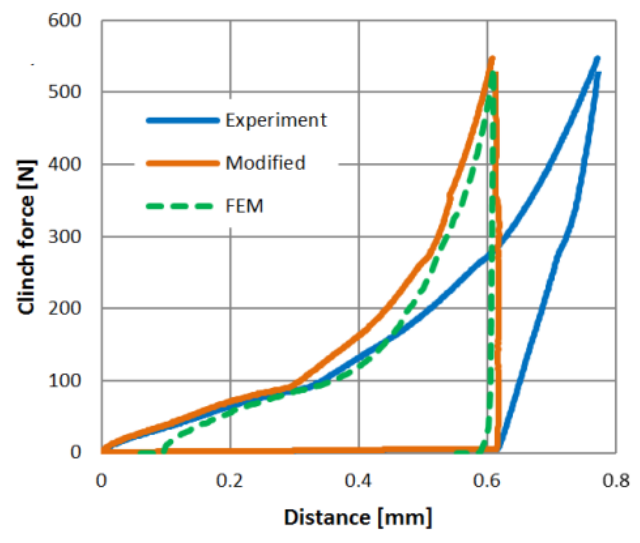

(a)

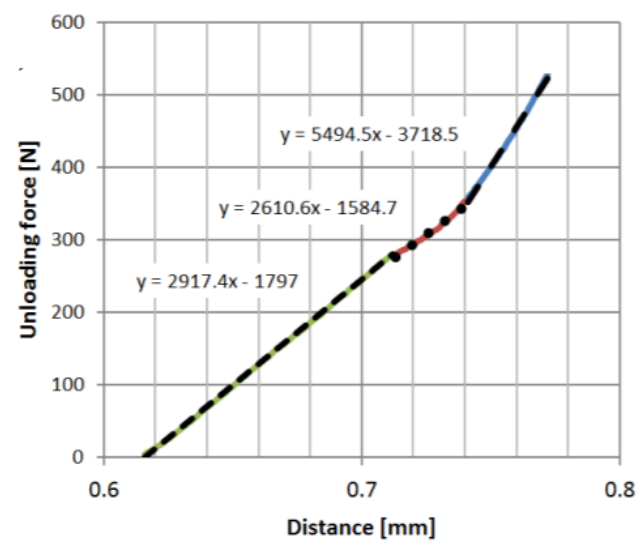

(b)

Fig. 12. Comparison of the force flow curves obtained by numerical simulation and experimental tests (a), unloading curve approximated with three straight lines (b)

The elastic correction of the position of the point corresponding to the process force is equal to the sum of all components of the elastic corrections up to the considered force point and is given by the formula:

$$
\Delta_{i}=\left\{\begin{array}{lc}
\Delta^{a} x_{i}=\sum_{i=1}^{a} \delta^{a} x_{i}, & i=1,2, \ldots, a \\
\Delta^{b} x_{i}=\Delta^{a} x_{a}+\sum_{i=a+1}^{b} \delta^{b} x_{i}, & i=a+1, a+2, \ldots, b \\
\Delta^{n} x_{i}=\Delta^{a} x_{a}+\Delta^{b} x_{b} \sum_{i=b+1}^{n} \delta^{n} x_{i}, & i=b+1, a+2, \ldots, n
\end{array}\right.
$$

where:

$\Delta^{a, b, n} x_{i}$ - corrections of displacement positions because of elastic deflection for three analysed ranges.

The recorded process force, which is a set of measuring points after the modification consisting of taking into account the elastic correction, is transformed into a set according to the equation:

$$
F=\left\{\left(x_{i}, Y_{i}\right), i=1,2, \ldots, n\right\} \quad \overrightarrow{\bmod } \quad F_{\text {mod }}=\left\{\left(x_{i}-\Delta_{i}, Y_{i}\right), i=1,2, \ldots, n\right\}
$$

where:

$F$ - set of measured points,

$F_{\text {mod }}$ - set of points taking into account the correction due to elastic deformations of the load system (machine, tools and tooling). 
This modification method has been applied to recorded process force. The modified curve was then compared with FEM results (Fig. 12a). The FEM curve on this graph has been artificially moved in such a way that the positions of the values of the maximum forces of the experiment and FEM agree, treating this point as a reference point for comparing the two courses. This procedure is associated with the instability of the testing machine recording of very small amounts of displacement and force, and the impact of the unstable friction in the initial punch movement. After this procedure, the curve was modified shows good agreement, which was considered as confirmation of the adopted method and recognition, that the results in clinching could be used further.

\section{Rapid Numerical Strength Test - RNST}

The proposed method of numerical joint loading test applies to axi-symmetrical joints and consists in numerical loading of the created joint model according to the diagram shown in figure 13. This process is very simple numerically and takes place in two simulation phases. The first phase, shown in figures 12a and $12 \mathrm{~b}$, consists in creating a joint of disks -4 and -5 . The second phase, shown in figures $12 \mathrm{c}$ and $12 \mathrm{~d}$, consists in moving the upper sheet -5 by a rigid slider -9 from the lower sheet -4 , which movement is limited by the rigid base -8 . This whole process is the FEM-axi-symmetrical modelling, whereby the joint shape and the state of stress, train and damage model are transferred directly from the first modelling phase. All material data are taken as Table II indicates. When loading the RNST joint, two types of joint damage occur:

- outcropping of the inner part of the joint by plastic deformation - figures $13 \mathrm{~b}$ and $13 \mathrm{c}$ under the influence of the axial force $F_{\mathrm{p}}$,

- detachment of the inner part of the joint due to a crack along the neck - characteristic is in this case, that the detached cap remains in the lower part.

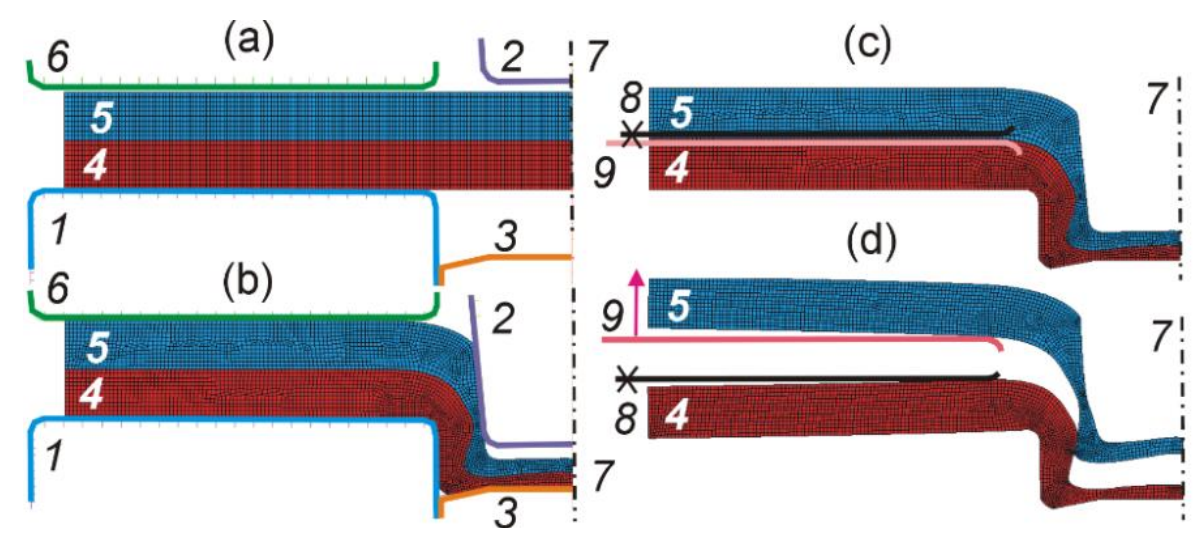

Fig. 13. Rapid numerical strength test scheme: a) Phase 1 - basic numerical model, 1 - die, 2 - upper punch, 3 - lower punch, 4 - lower sheet, 5 - upper sheet, 6 - blank holder, 7 - symmetry; b) Phase 1 - final step of clinching; c) Phase 2 - initial position of loading 8 - base, 9 - slider; d) Phase 2 - loading

The strength of the joint in the RNST test is defined as the maximum axial force stretching the joint. Its maximum value is the force $F_{\mathrm{c}}-$ Fig. $13 \mathrm{~d}$, needed to break - fracture - a stretched neck, which initial crosssection is determined by the $C_{t}$ parameter. Its size directly affects the maximum strength of the joint. However, this strength can be achieved when is met:

$$
F_{p} \geq F_{c}
$$

where:

$F_{\mathrm{p}}$ - axial force required for plastic separation of the joint,

$F_{c}$ - axial force necessary to separate by a crack.

The value of the force $F_{\mathrm{p}}$ depends directly on the parameter $u$ defining the clamp formed during clinching, Fig. 6a, and the COF. The influence of COF on joint loading by the RNST method is shown in figures 13a and 13c. A successive increase in COF causes an increase in the $F_{\mathrm{p}}$ until condition (5) is reached and the joint breaks. Processes were modelled using the RNST method and strain distributions and force courses of processes are shown in figure 14. It should be noted that in $P 1$ the upper neck of the plate did not break, which occurred in the case of $P 2$ and P3. The joint strength values obtained by the RNST method compared to the experimental values of $P T$ and $S T$ are shown in figure 15. The small value of the $R$ parameter at point $A$ is caused by a small value of the interlock (Table III), that the P1 creates. 

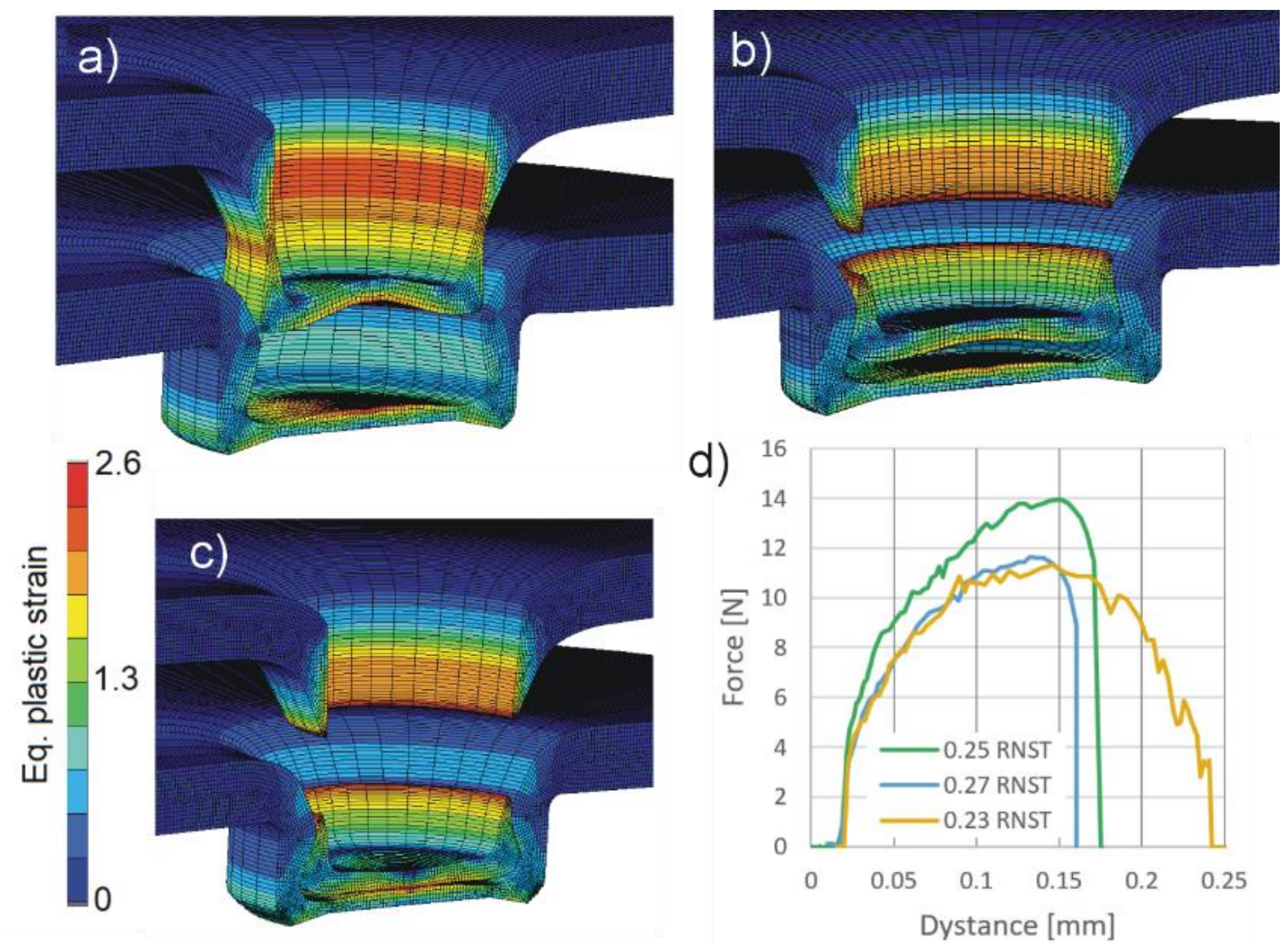

Fig. 14. RNST results: (a) Strain distribution in the sample $P 1, h_{c}=0.23$; (b) Strain distribution in the sample $P 2, h_{c}=0.25$; (c) Strain distribution in the sample $P 3, h_{c}=0.27$; (d) Process forces

It should be noted that RNST correctly recognized the mechanisms of joint tearing in the examined processes. Additionally, a mutual relation of tensile strength of the joint in RNTS are qualitatively similar to the results of $P T$ that are shown in figure 15.

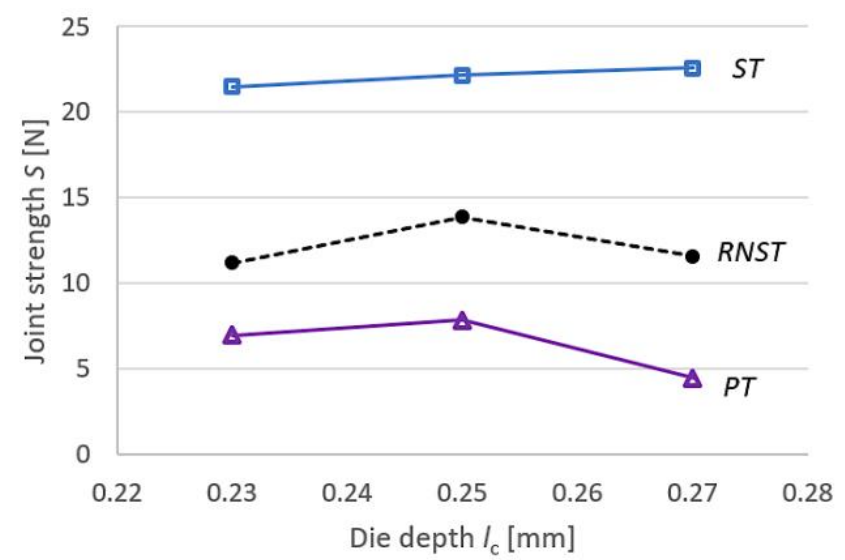

Fig. 15. Comparison of joint strengths obtained with experimental and numerical investigations

\section{Conclusions}

Preparation of the methodology and instrumentation for the study of micro-clinching processes, implementation of micro-clinching processes and processes of disruption of obtained joints as well as numerical modelling of these processes allows to draw the following conclusions.

- The method of micro-clinching analysis for axisymmetric joints has been proposed. The concept is based on a design of flexible micro-tooling system equipped with sets of micro-tools. According to that, designed tools geometry for clinching is parametrized, i.e. reduced for a small number of geometrical parameters. They are a reflection of geometrically simple tool components, which can generate modifications of the process. These tools based on commonly used industrial ones can be relatively easily manufactured with sufficient accuracy in the micro-scale. 
- With the use of flexible micro-tooling, a successful micro-clinching of silver sheets of thickness $0.18 \mathrm{~mm}$ has been conducted.

- The strength of the joints obtained in common tear tests such as peel test and shear test were determined.

- An effective numerical method for modelling the process of clinching and tearing the joint: Rapid Numerical Strength Test - RNTS has been presented. It consists of modelling the clinching process and then transferring the model and its features to the joint tearing process in $2 \mathrm{~d}$-axisymetrical conditions. Qualitative compliance of RNST modelling results with experimental results was obtained.

Author Contributions: conceptualization, W.S.; methodology, W.S. and H.B.; software, W.S.; validation, W.P., and H.B.; formal analysis, W.P.; investigation, W.P.; resources, W.P. and H.B.; data curation, W.P.; writing-original draft preparation, W.P.; writing-review and editing, H.B.; visualization, W.P.; supervision, W.P.; project administration, W.P.; funding acquisition, W.P.

Acknowledgments: The National Science Centre, Poland (UMO-2011/01 / B / ST8 / 07731) is financially supported by the National Science Centre Poland.

Conflicts of Interest: The authors declare no conflict of interest.

\section{References}

[1] [Lee S.J., Chang-Chien A., Cha S.W., O'Hayre R., Park Y.I., Saito Y., et al., Design and fabrication of a micro fuel cell array with 'flip-flop' interconnection. Journal of Power Sources Internet, 2002, Vol. 112(2), 410-8.

[2] Khanna R., MEMS fabrication perspectives from the MIT Microengine Project. Surface and Coatings Technology Internet, 2003, Vol. 163-164, 273-80.

[3] Rachkovskij D.A., Kussul E.M., Talayev S.A., Heat exchange in short microtubes and micro heat exchangers with low hydraulic losses. Microsystem Technologies Internet, 1998, Vol. 4(3), 151-8.

[4] Aoki I., Takahashi T., Mihara S., Yamagata Y., Higuchi T., Trial production of medical micro-tool by metal deformation processes using moulds. Proc. of the IEEE Micro Electro Mechanical Systems Internet, 1995, 344-9.

[5] Chován T., Guttman A., Microfabricated devices in biotechnology and biochemical processing. Trends in Biotechnology Internet, 2002, Vol. 20(3), 116-22.

[6] Rosen J., Hannaford B., Satava R.M., Surgical robotics: Systems applications and visions. Surgical Robotics: Systems Applications and Visions Internet, 2011, 1-819.

[7] Temel F.Z., Yesilyurt S., Simulation-based analysis of micro-robots swimming at the center and near the wall of circular mini-channels. Microfluidics and Nanofluidics Internet, 2013, Vol. 14(1-2), 287-98.

[8] Liang Q., Zhang D., Coppola G., Wang Y., Wei S., Ge Y., Multi-dimensional MEMS/micro sensor for force and moment sensing: A review. IEEE Sensors Journal Internet, 2014, Vol. 14(8), 2643-57.

[9] Shirmohammadi D., Movahedi M., Pouranvari M., Resistance spot welding of martensitic stainless steel: Effect of initial base metal microstructure on weld microstructure and mechanical performance. Materials Science and Engineering A, 2017, Vol. 703(June), 154-61. https://doi.org/10.1016/j.msea.2017.07.067

[10] Wei S.T., Liu R.D., Lv D., Xu R.J., Lin L., Guo J.Y., et al., Study on fibre laser spot welding of TRIP980 steel. Materials Science and Technology (United Kingdom) Internet, 2015, Vol. 31(11), 1271-81.

[11] Pardal G., Meco S., Dunn A., Williams S., Ganguly S., Hand D.P., et al., Laser spot welding of laser textured steel to aluminium. Journal of Materials Processing Technology, 2017, Vol. 241, 24-35.

https://doi.org/10.1016/j.jmatprotec.2016.10.025

[12] Liu B., Tian Y., Wang C., An R., Liu Y., Extremely fast formation of [Formula presented] intermetallic compounds in $\mathrm{Cu} / \mathrm{Sn} / \mathrm{Cu}$ system via a micro-resistance spot welding process. Journal of Alloys and Compounds, 2016, Vol. 687, 667-73. https://doi.org/10.1016/j.jallcom.2016.06.184

[13] Hozoorbakhsh A., Ismail M.I.S., Sarhan A.A.D.M., Bahadoran A., Aziz N.B.A., An investigation of heat transfer and fluid flow on laser micro-welding upon the thin stainless steel sheet (SUS304) using computational fluid dynamics (CFD). International Communications in Heat and Mass Transfer, 2016, Vol. 75, 328-40. https://doi.org/10.1016/j.icheatmasstransfer.2016.05.008

[14] Chen F., Gao X.P., Yue X.K., Tong G.Q., Effects of welding parameters on electrode element diffusion during micro-resistance spot welding. International Journal of Advanced Manufacturing Technology Internet, 2018, Vol. 95(58), 1597-606.

[15] Loginova I., Khalil A., Pozdniakov A., Solonin A., Zolotorevskiy V., Effect of pulse laser welding parameters and filler metal on microstructure and mechanical properties of Al-4.7Mg-0.32Mn-0.21Sc-0.1Zr alloy. Metals Internet, 2017, Vol. 7(12), 1-9.

[16] Skowrońska B., Chmielewski T., Golański D., Szulc J., Weldability of S700MC steel welded with the hybrid plasma + MAG method. Manufacturing Review Internet, 2020, Vol. 7, 4. 
[17] Martinson P., Daneshpour S., Koçak M., Riekehr S., Staron P., Residual stress analysis of laser spot welding of steel sheets. Materials and Design, 2009, Vol. 30(9), 3351-9. https://doi.org/10.1016/j.matdes.2009.03.041

[18] Di Lorenzo G., Landolfo R., Shear experimental response of new connecting systems for cold-formed structures. Journal of Constructional Steel Research Internet, 2004, Vol. 60(3-5), 561-79.

[19] Presz W., Cakco R., Application of complex micro-die for extrusion of micro-rivets for micro-joining. METAL 2017 - 26th International Conference on Metallurgy and Materials, Conference Proceedings Internet, 2017, Vol. 2017-Janua, 514-20.

[20] Presz W., Planetary riveting of electric bimetallic micro-contacts. Procedia Manufacturing, 2019, Vol. 27, 83-90. https://doi.org/10.1016/j.promfg.2018.12.048

[21] Presz W., Cacko R., Influence of micro-rivet manufacturing process on quality of micro-joint.In: AIP Conference Proceedings Internet, 2011.

[22] Presz W., Cacko R., Analysis of the influence of a rivet yield stress distribution on the micro-SPR joint - initial approach. Archives of Civil and Mechanical Engineering Internet, 2010, Vol. 10(4).

[23] Lee C.J., Lee J.M., Ryu H.Y., Lee K.H., Kim B.M., Ko D.C., Design of hole-clinching process for joining of dissimilar materials - Al6061-T4 alloy with DP780 steel, hot-pressed 22MnB5 steel, and carbon fiber reinforced plastic. Journal of Materials Processing Technology, 2014, Vol. 214(10), 2169-78.

https://doi.org/10.1016/j.jmatprotec.2014.03.032

[24] Lambiase F., Di Ilio A., Paoletti A., Joining aluminium alloys with reduced ductility by mechanical clinching. International Journal of Advanced Manufacturing Technology Internet, 2015, Vol. 77(5-8), 1295-304.

[25] Chmielewski T., Hudycz M., Krajewski A., Salaciński T., Skowrońska B., Świercz R., Structure investigation of titanium metallization coating deposited onto aln ceramics substrate by means of friction surfacing process. Coatings Internet, 2019, Vol. 9(12).

[26] Chmielewski T., Siwek P., Chmielewski M., Piątkowska A., Grabias A., Golański D., Structure and selected properties of arc sprayed coatings containing in-situ fabricated Fe-Al intermetallic phases. Metals Internet, 2018, Vol. 8(12).

[27] Kim J.B., Kim H.K., Fatigue behaviour of clinched joints in a steel sheet. Fatigue and Fracture of Engineering Materials and Structures Internet, 2015, Vol. 38(6), 661-72.

[28] Vitzthum S., Hiller M., Volk W., Experimental investigation of the scalability of roller-clinching processes with regard to joint strength and failure mode. Materialwissenschaft und Werkstofftechnik Internet, 2019, Vol. 50(8), 101526.

[29] Abe Y., Ishihata S., Maeda T., Mori K.I., Mechanical clinching process using preforming of lower sheet for improvement of joinability. Procedia Manufacturing, 2018, Vol. 15, 1360-7. https://doi.org/10.1016/j.promfg.2018.07.347

[30] Gerstmann T., Awiszus B., Recent developments in flat-clinching. Computational Materials Science, 2014, Vol. 81, 39-44. https://doi.org/10.1016/j.commatsci.2013.07.013

[31] Cumin J., Samardžić I., Dunđer M., Mechanical clinching process stress and strain in the clinching of EN-AW5754 (AlMg3), and EN AW-5019 (AlMg5) metal plates. Metalurgija Internet, 2018, Vol. 57(1-2), 107-10.

[32] Mucha J., Kašcák L., Spišák E., Joining the car-body sheets using clinching process with various thickness and mechanical property arrangements. Archives of Civil and Mechanical Engineering Internet, 2011, Vol. 11(1), $135-48$.

[33] Geiger M., Kleiner M., Eckstein R., Tiesler N., Engel U., Microforming. CIRP Annals - Manufacturing Technology Internet, 2001, Vol. 50(2), 445-62.

[34] Eichenhueller B., Egerer E., Engel U., Microforming at elevated temperature - Forming and material behaviour. International Journal of Advanced Manufacturing Technology Internet, 2007, Vol. 33(1-2), 119-24.

[35] Wang C., Guo B., Shan D., Friction related size-effect in microforming -A review. Manufacturing Review Internet, 2014, Vol. 1.

[36] Ran J.Q., Fu M.W., Chan W.L., The influence of size effect on the ductile fracture in micro-scaled plastic deformation. International Journal of Plasticity Internet, 2013, Vol. 41, 65-81.

[37] Raulea L. V., Goijaerts A.M., Govaert L.E., Baaijens F.P.T., Size effects in the processing of thin metal sheets. Journal of Materials Processing Technology Internet, 2001, Vol. 115(1), 44-8.

[38] W P., A R., The influence of grain size on surface quality of microformed components.In: Juster N, Rosochowski A, editors. The 9th International Conference on Material Forming: ESAFORM 2006 Internet, Glasgow, U.K, Publishing House 'Akapit', Krokow, Poland, 2006. p. 587-90.

[39] Muster A., Presz W., Influence of initial surface roughness on galling behaviour of a steel-steel couple. Scandinavian Journal of Metallurgy Internet, 1999.

[40] Presz W., Rosochowska M., Application of semi-physical modeling of interface surface roughness in design of pre-stressed microforming dies. Procedia Engineering Internet, 2017, Vol. 207(September), 1004-9. 
[41] Presz W., Scale effect in design of the pre-stressed micro-dies for microforming. Computer Methods in Materials Science Internet, 2016, Vol. 16(4), 196-203.

[42] Kocańda A., Presz W., Adamczyk G., Czyzewski P., Mazurek W., Contact pressure distribution in upsetting of compound metals. Journal of Materials Processing Technology Internet, 1996, Vol. 60(1-4).

[43] Lee C.J., Kim J.Y., Lee S.K., Ko D.C., Kim B.M., Parametric study on mechanical clinching process for joining aluminum alloy and high-strength steel sheets. Journal of Mechanical Science and Technology Internet, 2010, Vol. 24(1), 123-6.

[44] Lambiase F., Di Ilio A., Optimization of the clinching tools by means of integrated fe modeling and artificial intelligence techniques. Procedia CIRP, 2013, Vol. 12, 163-8. https://doi.org/10.1016/j.procir.2013.09.029

[45] Roux E., Bouchard P.O., Kriging metamodel global optimization of clinching joining processes accounting for ductile damage. Journal of Materials Processing Technology, 2013, Vol. 213(7), 1038-47.

https://doi.org/10.1016/j.jmatprotec.2013.01.018

[46] Wang X., Li X., Shen Z., Ma Y., Liu H., Finite element simulation on investigations, modeling, and multiobjective optimization for clinch joining process design accounting for process parameters and design constraints. International Journal of Advanced Manufacturing Technology Internet, 2018, Vol. 96(9-12), 3481-501.

[47] Engel U., Tribology in microforming. Wear Internet, 2006, Vol. 260(3), 265-73.

[48] Presz W., Rosochowski A., The influence of grain size on surface quality of microformed components.In: The 9th International Conference on Material Forming: ESAFORM 2006, Glasgow, UK Internet, Akapit, Kraków, Poland, 2006. p. 587-90.

[49] Paćko P., Uhl T., Multiscale approach to structure damage modelling. Journal of Theoretical and Applied Mechanics Internet, 2011, Vol. 49(1), 243-64.

[50] Christiansen P., Nielsen C. V., Martins P.A.F., Bay N., Predicting the onset of cracks in bulk metal forming by ductile damage criteria. Procedia Engineering, 2017, Vol. 207, 2048-53.

https://doi.org/10.1016/j.proeng.2017.10.1106

[51] Presz W., Cacko R., Bimetallic micro-punches for micro-blanking processes. Archives of Metallurgy and Materials Internet, 2018, Vol. 63(1), 29-34.

[52] Cacko R., Czyżewski P., Kocańda A. Initial optimization of self-piercing riveting process by means of FEM. Steel Grips, 2004, 307-310.

(C) 2020 by the authors. Submitted for possible open access publication under the terms and conditions of the Creative Commons Attribution (CC BY) license (http://creativecommons.org/licenses/by/4.0/). 